\title{
Futuros educadores ou professores? Um estudo sobre as representações sociais dos acadêmicos de letras da Universidade Federal do Amazonas/Humaitá sobre a carreira docente
}

\begin{tabular}{c}
\hline Future educators or teachers? A study on \\
the social representations of the Language \\
Course academics from Universidade \\
Federal do Amazonas/Humaitá on teaching \\
career
\end{tabular}

Fabiana Soares Fernandes ${ }^{1}$

RESUMO

O presente artigo apresenta o resultado de uma pesquisa realizada na Universidade Federal do Amazonas, no Campus Vale do Rio Madeira, localizado no município de Humaitá/AM. Este estudo teve por objetivo investigar quais são as representações sociais sobre a "Carreira Docente", dos acadêmicos da Licenciatura dupla em Letras - Língua e Literatura Brasileira e Inglesa, levando em consideração o professor como sujeito do conhecimento e importante ator social no contexto escolar. A metodologia utilizada foi quali-quantitativa. O instrumento, uma entrevista semiestruturada composta por duas partes: na primeira parte foi feita a identificação e os discentes puderam elencar seus motivos e influencias em sua escolha pelo curso em questão; (esses aspectos foram tabulados quantitativamente). Na segunda parte fez-se uso da "palavra indutora" que permitiu aos atores expressarem suas representações sobre a Carreira Docente (esses dados foram analisados de forma qualitativa, uma vez que o objetivo era conhecer

1 Psicóloga, doutoranda da Universidade do Porto/Portugal, professora da Universidade Federal do Amazonas, vinculada ao Colegiado de Pedagogia no Instituto de Educação, Agricultura e Ambiente, Brasil. 
a subjetividade envolvida no discurso). A análise dos dados coletados nos permitiu conhecer variadas motivações para o ingresso no curso, além de constatar que muitos alunos não desejavam estar cursando essa Licenciatura o que nos leva a uma preocupante reflexão sobre o futuro comprometimento desses indivíduos com a educação.

Palavras-chave: escolha profissional; motivações; representações sociais.

\begin{abstract}
This article presents the results of a research accomplished at the Federal University of Amazonas, Campus Vale do Rio Madeira, located in the city of Humaitá/AM. This study aimed to investigate what the social representations on the Teaching Career of the academics of the double degree in Portuguese and English Language and Literature are, taking into consideration the teacher as the subject of knowledge and as an important social actor in the school context. The methodology that we used was both qualitative and quantitative. The instrument was a semi-structured interview consisting of two parts: the first part was built to identify the students' choice and they were able to list their reasons and their influences on their choice for the course in question, (these aspects were tabulated quantitatively). In the second part it was used the "inducing word" that allowed the actors to express their representations about teaching profession (these data were analyzed qualitatively, since the objective was to understand the subjectivity involved in speech). The analysis of the collected data allowed us to find various reasons for the ingress in the course, in addition, we could notice that many students did not want to be taking this degree which leads us to a worrying reflection on the future commitment of these individuals with education.
\end{abstract}

Keywords: professional choice; motivations; social representations.

\title{
Introdução
}

Ser professor, o que isso significa? Será que todos veem os professores da mesma maneira? Porque alguns escolhem ser professores enquanto outros optam por ser enfermeiros, agrônomos, dentistas, advogados, médicos, engenheiros, etc.?

O presente estudo teve por objetivo investigar quais são as representações sociais sobre a "Carreira Docente", dos acadêmicos da Licenciatura dupla em 
Letras - Língua e Literatura Brasileira e Inglesa, levando em consideração o professor como sujeito do conhecimento e importante ator social no contexto escolar.

O contexto em que se realizou essa pesquisa foi o Campus Vale do Rio Madeira, da Universidade Federal do Amazonas, localizado no município de Humaitá. Este localiza-se no sul do estado do Amazonas. O Campus foi implantado no segundo semestre de 2006, como parte do programa de interiorização das Universidades do Ministério da Educação. Nessa fase de implantação o Campus oferece 06 cursos de graduação, sendo 04 licenciaturas e 02 bacharelados.

A motivação para a realização desse estudo foi perceber, no discurso dos discentes das turmas em que ministrei disciplinas, a falta de informação e de interesse de alguns sobre o curso que estavam frequentando. Isso é demonstrado com aspectos como o fato de alguns não terem claro que as licenciaturas são cursos voltados à formação de professores, até o fato de terem escolhido o curso não por se interessarem por ele, mas para não ficar em casa ou porque não há no Campus o curso de seus sonhos, entre outros motivos. Essas e outras colocações me chamaram a atenção e me preocuparam tanto como psicóloga como educadora. Porque esses jovens estão abrindo mão dos seus sonhos? O que esperam de seu futuro profissional? Que profissionais estamos formando? Que professores estarão atuando nas escolas do município daqui a 2, 3 ou 4 anos?

Naturalmente, não foi nessa pesquisa que pude responder a todas as inquietações que vem fervilhando em meu pensamento nos últimos anos, até porque são muitos aspectos a serem investigados. Assim, delimitei nesta pesquisa, a busca pela compreensão das Representações Sociais que os discentes do Curso de Licenciatura em Língua e Literatura Brasileira e Inglesa têm a respeito da Carreira Docente. Os objetivos almejados foram conhecer os motivos que levaram os discentes a escolherem esse curso, que pessoas mais os influenciaram nessa escolha, o que pensam da Carreira Docente e porque escolheram essa carreira.

Busquei compreender na Teoria das Representações Sociais como são construídas as Representações, que fatores influenciam nessa construção, buscando a partir dessa teoria um encontro com a subjetividade dos discentes. A fim de estabelecer um comparativo, investiguei obras e pesquisas que tratassem do perfil e papel do professor, a fim de verificar o que outros discentes pensam sobre a Carreira Docente, qual imagem do professor que está consolidada, e porque as pessoas escolhem ou rechaçam essa carreira.

O estudo das representações pode contribuir para a organização (e/ou reorganização) do programa do curso, demonstrando as possíveis necessidades em relação à formação inicial, ressaltando o seu papel (do curso) na construção da identidade profissional dos futuros professores.

A metodologia utilizada foi quali-quantitativa. O instrumento, uma 
entrevista semiestruturada composta por duas partes: na primeira foi feita a identificação e os discentes puderam elencar seus motivos e influências em sua escolha pelo curso em questão (esses aspectos foram tabulados quantitativamente). Na segunda parte fez-se uso da "palavra indutora" que permitiu aos atores expressarem suas representações sobre a Carreira Docente (esses dados foram analisados de forma qualitativa, uma vez que o objetivo é conhecer a subjetividade envolvida no discurso)

A coleta de dados se deu no Campus de Humaitá, na primeira quinzena do mês de março de 2009. A amostra foi composta por 90 discentes que se encontram regularmente matriculados e frequentando o curso, que no momento se encontravam no $2^{\circ}$., $4^{\circ}$. e $6^{\circ}$. períodos. Os alunos foram convidados a participar da pesquisa, de maneira voluntária e anônima. A análise dos dados coletados nos permitiu conhecer variadas motivações para o ingresso no curso, que será descrito ao longo do artigo, além de constatar que muitos não desejavam estar cursando essa Licenciatura, o que nos leva a uma preocupante reflexão sobre o futuro comprometimento desses indivíduos com a educação.

\section{O papel do professor}

Refletindo inicialmente sobre a função do professor, é possível perceber que esta ela é necessária, principalmente se levarmos em consideração o aumento das atribuições da escola, a valorização da criança e a crescente exigência de qualificação no mercado de trabalho.

Segundo Vasconcellos (2001), a análise de nossa realidade educacional e social torna evidente a necessidade do professor e a importância de seu trabalho. Ao mesmo tempo, revela o quão complexa é essa atividade, "já que implica participar da formação do caráter, da personalidade, da consciência, da cidadania do educando [...] tendo como mediação os conhecimentos historicamente elaborados e relevantes" (p.47). O professor trabalha com conceitos, imagens, valores, ideais, deveres, direitos, enfim, uma série de aspectos que tornam sua atuação complexa, o que exige do professor "uma revisão da compreensão de sua atividade e de sua atitude profissional" (p.47).

Cunha (2006) afirma que a importância e o significado do papel do professor não dependem exclusivamente dele, uma vez que este será atribuído pela sociedade que o produz e, a importância dada a ele vai variar em função dos valores e interesses que caracterizam esta sociedade em determinada época. De acordo com essa autora, "a sociedade contemporânea já produziu a ideia do 
professor-sacerdote, colocando a sua tarefa em nível de missão, semelhante ao trabalho dos religiosos. A mistificação do professor foi produto social e interferiu no seu modo de ser e de agir." (CUNHA, 2006, p. 28).

Essa visão da profissão como missão, como vocacional, acabava desprezando as necessidades tipicamente humanas de ganhar a vida por meio de uma profissão. Nessa pesquisa, essa visão só foi expressa por 04 dos discentes $(4,4 \%$ do total), o que demonstra a mudança de postura, de compreensão do papel do professor como um trabalhador assalariado que vende sua mão de obra e/ou produto de seu trabalho. Para Cunha (2006, p.28), "Esta perspectiva inclui a ideia de que o trabalho intelectual também está incluído no processo de produção [...]".

Marques (2003, p.57) esclarece que "mesmo que as evidências mostrem o educador hoje como um profissional entre os demais, insiste-se em distingui-lo por algo mais. 'Não basta ser profissional': é o que se diz". Com essa colocação, o autor nos chama atenção para que exercer uma profissão, ou seja, tirar dela seu sustento, não pode estar separado de um sentido, de um valor social, de uma realização, caso contrário corre-se o risco "de o trabalho, a profissão, converter-se em forma de alienação pessoal e social”. (MARQUES, 2003, p.57)

$\mathrm{O}$ autor enfatiza ainda que no contexto em que nos encontramos, de rápidas transformações, a educação exige cada vez mais um profissional preparado e dedicado, assim: "Todo professor/educador deve ser profissional especializado em educação, educador por inteiro, capaz de conduzir o inteiro processo educativo: do pensar ao agir e fazer avaliar [...]" (MARQUES, 2003, p. 58). O futuro professor precisa ter claro o seu papel na sociedade, como se dará a distribuição do seu conhecimento, suas responsabilidades e comprometimentos. A maneira com que ele vive e percebe as regras educacionais e sociais vai determinar sua maneira de agir. Marques (2003) destaca ainda que:

Em seu processo formativo, a vida pessoal de cada educador é evocada para as suas responsabilidades socias, de forma tal que se correlacionem a personalidade de cada um e a inserção vital dele no mundo da vida como estruturação do imaginário inaugural e como espaço compartilhado por todos; e na qualidade de teia de relações colocada como suporte das identidades inter e intrasubjetivas. (MARQUES, 2003, p.61)

Garcia, Hypólito e Vieira (2005) enfatizam que a identidade profissional dos docentes deve ser entendida como uma construção social, e como tal é influenciada por muitos fatores. A interação desses fatores dará origem às representações sociais que os docentes farão de si e de sua função. Natural- 
mente, essas representações que são recheadas por componentes conscientes e inconscientes trazem em seu bojo reminiscências de suas histórias de vida e experiências anteriores.

Na pesquisa realizada por Cunha (2006), foi possível constatar que os professores entrevistados são bastante influenciados no seu comportamento pelos antigos professores. Isso nos leva a lembrar que o educador traz consigo parte de sua história, de suas vivências, expectativas, desejos, frustrações. Todo o seu contexto influencia diretamente sua atuação, e como ele é um modelo, mesmo que não tenha consciência disto, poderá influenciar o comportamento futuro de seus alunos.

Na pesquisa que aqui se apresenta, essa influência apareceu em dois momentos, inicialmente quando foi feito o questionamento a cerca de que pessoas influenciaram os discentes na escolha do curso. Dezenove entrevistados (21\%) declararam que os professores do Ensino Médio os influenciaram, e, ao analisarmos os dados subjetivos, perguntamos "porque você quer ser professor?" e uma entrevistada afirmou: "Para não cometer, na vida dos alunos, algumas deficiências que muitos professores deixaram no meu processo de aprendizagem." A influência exercida pelos antigos professores só não foi maior do que a exercida pela família, aspecto esse que será discutido adiante.

\section{Gráfico 1}

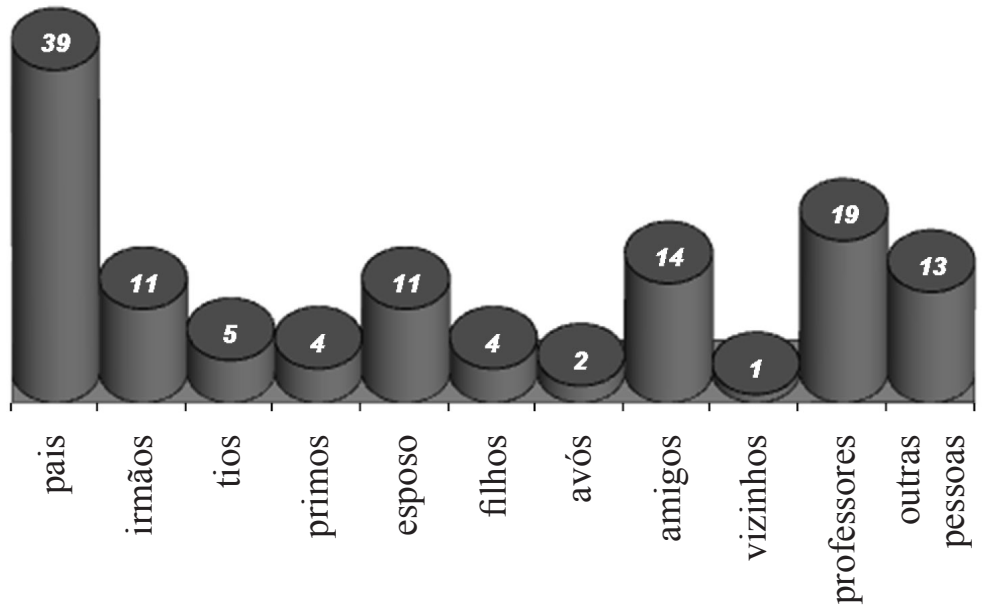


Cunha (2006) destaca ainda, na referida pesquisa, que esta (influência) é

uma vertente que precisa ser considerada quando se pensa na formação de professores. Também vale ressaltar o quanto se aprende pela prática do cotidiano, pela convivência e o quanto o professor precisa estar consciente disso. De alguma forma vê-se uma certa reprodução do comportamento docente. E, se isto tem aspectos positivos, também há o risco da repetição de práticas sem uma reflexão sobre elas.( CUNHA, 2006, p. 92).

Para Vasconcellos (2001) a significação é um processo de construção de sentido que se estabelece a partir das representações mentais do indivíduo e do objeto/situação real. Para ele,

a busca de sentido é algo que, em diferentes medidas, acompanha a pessoa o tempo todo, estando, pois, articulada à atividade do homem se autoproduzir, às suas diferentes formas de relação e/ou intervenção no mundo. A significação vai implicar, pois, em se fazer relações do objeto ou situação com a existência, tanto passada (experiências, representações prévias), quanto presente (situação de conhecimento) e futura (aspirações, desejos, expectativas); não é possível, portanto, separar o sujeito epistêmico do sujeito concreto. (VASCONCELLOS, 2001, p.51).

Foi nesse sentido que se buscou, nesta pesquisa, utilizar como referencial teórico, a Teoria das Representações Sociais, a fim de compreender esse processo de construção de sentido. Esse aspecto teórico será aprofundado um pouco mais adiante.

À guisa de conclusão sobre o papel do professor, Vasconcellos (2001) conclui que "o professor compreende que não é ele que "deposita" o conhecimento na cabeça do educando", mas que é necessário direcionar a construção desse conhecimento. O professor faz isso a partir do momento em que provoca no aluno certas necessidades de conhecimento, ao provocar contradições, desequilíbrios. Esse profissional precisa disponibilizar aos alunos o contato com diversos objetos e situações novas para que ele consiga procurar respostas aos problemas que lhe forem propostos, de maneira crítica, criativa, significativa e duradoura. Cabe ao professor o papel de mediador (como já dizia Vygotsky) entre o novo e o velho, estabelecendo relações do conhecimento formal com sua aplicabilidade no dia a dia. 
Para Vasconcellos (2001), um professor engajado com a educação está imerso na dinâmica do amor pelos alunos, pelo conhecimento, pelo ensinar, por si, pela sociedade e pela vida.

Amar significa desejar ardentemente que o outro aprenda a ter prazer nisto; ter prazer em partilhar com o outro um trecho do percurso que já fez (e que continua fazendo), tendo consciência de que o caminho do outro terá suas peculiaridades. Esta satisfação é que vai também ajudar a suportar a fadiga da atividade e a sustentar a necessária paciência pelas (várias) formas (e) ritmos de apreensão do outro. (VASCONCELLOS, 2001, p. 63)

\section{A escolha da carreira}

O que leva uma pessoa a escolher o curso de graduação que irá frequentar durante os próximos 04 ou 5 anos?

Vasconcellos (2001) considera que o ponto de partida para o engajamento num processo é o desejo de participar e o compromisso que daí decorre, esse momento "corresponde ao querer, à significação, motivação, energização, despertar a paixão, erotizar o trabalho, a partir do nosso contato com a realidade e com outros companheiros que estão na mesma caminhada [...]"(VASCONCELLOS, 2001, p.48).

Cabe nesse momento citar Alves (2006) que, ao falar sobre as profissões que desapareceram com o avanço das cidades e das indústrias, inicia seu discurso sobre a formação do educador dizendo:

Educadores onde estarão? Em que covas terão se escondido? Professores, há aos milhares. Mas o professor é profissão, não é algo que se define por dentro, por amor. Educador, ao contrário, não é profissão; é vocação. E toda vocação nasce de um grande amor, de uma grande esperança (ALVES, 2006, p. 16).

Essas colocações nos levam a uma importante reflexão diante do percentual de discentes que, apesar de estarem cursando uma licenciatura, afirmam que 
não querem ser professores, e que antes de iniciar a graduação não tinham essa vontade (39\% gráfico 2).

\section{Gráfico 2 Já havia pensado em ser professor antes de iniciar o curso?}

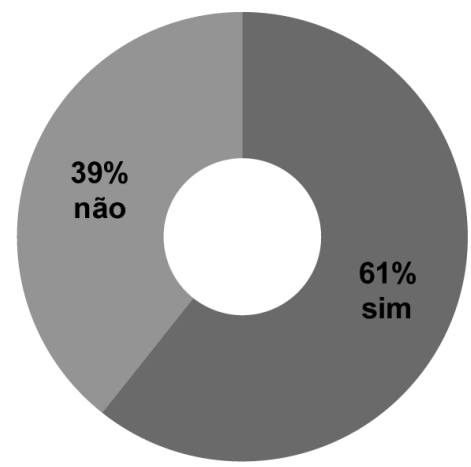

Em poucos anos esses indivíduos estarão com seus diplomas nas mãos diante de um mercado de trabalho não muito promissor. O questionamento que levanto nesse momento é: apesar desses discentes terem declarado que não querem ser professores, ou seja, de não terem o desejo e o compromisso com a educação como citou Vasconcellos (2001), será que vão dispensar o trabalho como professores caso se deparem com essa oportunidade ao término do curso? E se aceitarem, como serão suas atuações? Serão meros transmissores de informações? Simples professores em oposição aos educadores como distingue Alves (2006) ao diferenciar os Jequitibás dos Eucaliptos?

Infelizmente, esses não são questionamentos aleatórios, um dos discentes (talvez a resposta mais chocante) chegou a afirmar: "Não pretendo ser professor, mas não descarto a possibilidade caso esteja desempregado".

Apesar dessa negação ou discriminação com a Carreira Docente observada acima, dos 35 discentes (39\% do total de entrevistados) que afirmaram não pensar em ser professor antes de iniciar o curso, 15 (43\% desses) mudaram de opinião ao longo do curso e 06 (17\%) estão repensando suas posturas e opções iniciais. Permanecem não querendo seguir a Carreira Docente 07 discentes (20\%) e outros 07 (20\%) não responderam.

Para falar desse querer, desse desejo em ser professor, Vasconcellos (2001) em seu texto referencia Gramsci quando essa afirmava que seria um erro pensar ser possível conhecer sem estar apaixonado por esse conhecimento. $\mathrm{O}$ desejo pelo conhecer é fundamental para o exercício profissional do professor uma vez que é essa paixão que moverá seu intelecto. 
Diante desse "não desejo" de ser professor, questionamos o porquê da escolha de uma licenciatura como curso de graduação. Segue abaixo os dados encontrados (gráfico 3 ).

Embora apenas 22 entrevistados tenham declarado inicialmente que escolheram uma Licenciatura porque "sempre quiseram ser professores" (como foi possível observar no gráfico 3), quando foram perguntados por que querem ser professores, os dados encontrados foram positivos. $37 \%$ dos entrevistados afirmaram que querem contribuir com o desenvolvimento de sua região e do Brasil: querem ajudar as pessoas a mudarem e melhorarem suas vidas; outros $20 \%$ afirmaram que desejam ensinar e aprender com seus alunos, compartilhar tudo o que estão aprendendo, numa interação constante, entre outros motivos que podem ser observados no gráfico 4 .

\section{Gráfico $4 \quad$ Por que quero ser professor?}

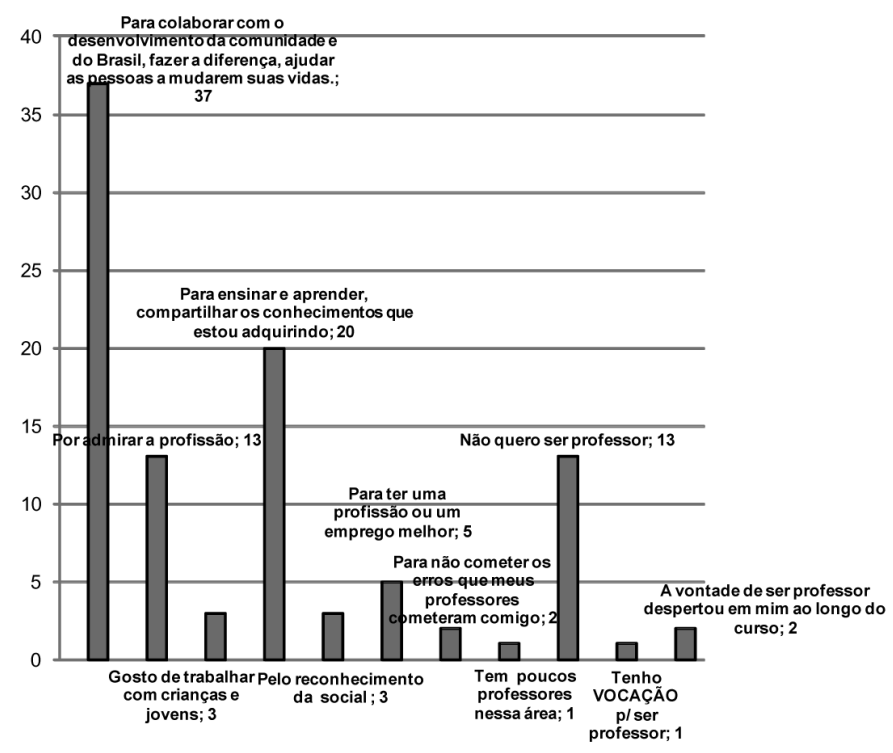

\section{A influência da família}

Segundo Almeida e Pinho (2008), "são muitos os fatores que influem na escolha de uma profissão, desde características pessoais a convicções políticas e religiosas, valores, crenças, contexto socioeconômico, família e pares." Os autores citam que muitas pesquisas vêm demonstrando que a família tem grande 
influência nessa escolha, podendo ajudar ou dificultar a decisão do jovem. Este observa a profissão dos pais e como estes a vivenciam, estabelecendo conceitos e valores a cerda delas.

Algumas vezes essa influência da família é sutil, aparece através dos comentários sobre as diversas profissões, por exemplo, outras vezes são diretas e manipuladoras, exigindo que os filhos dêem continuidade à carreira dos pais ou avós. Essas influências são mais acentuadas (e complicadoras) na adolescência, uma vez que essa fase, por si só já é uma fase de transição e conflitos. Ao mesmo tempo em que o jovem está construindo sua identidade, também precisa construir sua identidade profissional, que conforme afirma Lisboa (1997, apud ALMEIDA; PINHO, 2008, p. 176) está "diretamente vinculada à identidade pessoal, pois ambas incluem todas as identificações feitas pelo indivíduo ao longo da vida."

Mizukami (apud REALI; MIZUKAMI, 1996, p. 69), em um estudo de caso realizado com 05 professoras aposentadas, percebeu que quatro das cinco afirmaram que a escolha do magistério se deu na infância ou na adolescência. $\mathrm{O}$ ambiente familiar foi muito importante nessa escolha, exercendo influência tanto "no que se refere ao magistério em si e à área específica em que o magistério seria exercido quanto em relação a modelos e estímulos relacionados à profissão".

$\mathrm{Na}$ pesquisa aqui apresentada, a família apareceu como influenciadora em 76 entrevistas, ou seja, em $84,4 \%$ do total, sendo dada maior ênfase aos pais que foram citados em $51,31 \%$, seguido dos irmãos e esposo com $14,5 \%$ cada. Tios, primos, filhos e avós somam os outros $19,7 \%$.

\section{Representação social da carreira docente para os alunos pesquisa- dos}

O primeiro teórico a utilizar o conceito de representação social foi Durkheim, o qual considerava a sociedade uma síntese "sui generis" que dá origem a fenômenos novos que residem na sociedade, ou seja, a sociedade é que os produz e não suas partes. Moscovici utilizou inicialmente o embasamento teórico de Durkheim, porém com o tempo se afastou da perspectiva sociológica e aproximou-se mais da psicologia e das ciências sociais.

A representação social considera que o conhecimento se constrói no senso comum, pois através da experiência do grupo que se forma o conceito sobre determinado fato ou evento que é constituído na relação sujeito-objeto-sujeito. Não existem saberes que sejam desvinculados do contexto de uma relação. Dessa forma, não se deve "na teoria social, trabalhar com categoria contexto 
social como se contexto social fosse apenas uma abstração ou uma variável a mais." (JOVCHELOVICTH, 2001, p.23)

Mauricio (2009, p.116) referencia Jodelet ao justificar o uso da representação social "como uma forma de conhecimento, um saber prático que se refere exatamente à experiência a partir da qual ele se produz e serve para agir sobre o mundo."

Segundo Jodelet (1989 apud MAURICIO, 2009, p.117),

a representação social é sempre representação de alguma coisa e de alguém na qual as características do sujeito e do objeto se manifestam. A representação social simboliza e interpreta o objeto, substituindo-o e atribuindo-lhe sentido. A representação é construção e expressão do sujeito que se dá por meio de processos cognitivos e psíquicos, com a particularidade de incorporar, na análise dos processos, a pertença e a participação social e cultural do sujeito (JODELET, 1989 apud MAURICIO, 2009, p.117).

A construção das representações sociais se dá através de dois processos: a objetivação e a ancoragem. Segundo Moscovici (1978) a objetivação faz com que:

[...] se torne real um esquema conceptual, com que se dê a uma imagem uma contrapartida material, resultado que tem, em primeiro lugar, flexibilidade cognitiva: o estoque de indícios e de significantes que uma pessoa recebe, emite e movimenta no ciclo das informações pode tornar-se superabundante (MOSCOVICI, 1978, p. 110)

Já o processo de amarração ou ancoragem consiste na incorporação de novos elementos de saber dentro de um conjunto de categorias familiares, isto é, consiste em trazer para categorias e imagens conhecidas o que ainda não está classificado e nomeado. Segundo Moscovici (1978, p.173) “[...] mediante o processo de amarração, a sociedade converte o objeto social num instrumento de que ela pode dispor, e esse objeto social é colocado numa escala de preferência nas relações sociais existentes".

Uma das possibilidades de se verificar as representações dos discentes sobre a Carreira Docente, ou seja, compreender como se deu o processo de amarração, é através do uso de palavra indutora e/ou logotipo, que permite aos 
atores representar esse objeto. Ramos (2003) utilizou esse mecanismo em sua pesquisa, quando quis compreender a representação social que as mulheres vítimas de violência conjugal tinham da mulher. A fim de compreender melhor esse representar, utilizaremos a explicação dessa autora:

Representar um objeto é compartilhar um conhecimento do mundo social. Esse compartilhar permite que os indivíduos troquem informações, ideias, crenças, valores e organizem o produto dessas trocas ou esquemas que sejam assimiláveis e compreensíveis para todos os envolvidos nesse processo. (RAMOS, 2003, p.139)

Conforme explica Ramos (2003), as representações sociais são construídas a partir do conjunto de ações compartilhadas por determinado grupo e expressam suas crenças, valores e sentimentos em relação aos objetos do mundo social. O seu estudo possibilita compreender a interação entre o universo individual e as condições sociais nas quais os indivíduos interagem. Permite, ainda, compreender os processos que intervêm na adaptação sócio-cognitiva dos indivíduos às realidades cotidianas e ao seu ambiente social e ideológico.

Pimenta (1997, p.42) assegura que quando os alunos chegam à licenciatura já tem saberes sobre o que é ser professor. Os saberes de sua experiência de alunos de diferentes professores que conheceram ao longo de sua vida escolar:

Também sabem sobre o ser professor através da experiência socialmente acumulada: as mudanças históricas da profissão, o exercício profissional em diferentes escolas, a não valorização social e financeira dos professores, as dificuldades de estar diante de turmas de crianças e jovens turbulentos, em escolas precárias; sabem um pouco sobre as representações e os estereótipos que a sociedade tem dos professores através dos meios de comunicação. (PIMENTA, 1997, p. 43)

Ao analisarmos as considerações do autor, é possível perceber que para ele a imagem da Carreira Docente é de uma carreira complexa, repleta de dificuldades, insatisfações e estigmas, na qual apenas aqueles que tem "DOM" para a docência conseguem seguir e se realizar.

No entanto, os dados coletados demonstram que os discentes representam o professor como aquele ser que domina um conhecimento e que a partir dele, ensina aqueles que não o dominam. Embora essa seja a imagem clássica do 
professor como transmissor de conhecimento, não foi essa a única função atribuída ao professor pelos entrevistados. Os discentes percebem que o professor precisar ser capaz de utilizar o seu conhecimento, numa troca constante com seus alunos, ao passo que ao mesmo tempo em que ensina também aprende.

O professor é visto como um profissional que precisa estar em constante qualificação diante das rápidas mudanças pelas quais o mundo vem passando. Essa exigência deixa claro que não basta ter "dom" ou "vocação" para a docência, mas que acima de tudo tem que haver um querer, um desejo, porque são esses aspectos que vão permitir que o professor supere as dificuldades que surgirão ao longo de sua carreira.

A figura do professor está representada também como um agente de transformação, capaz de influenciar pessoas, gerar opiniões, mudar uma sociedade, além de participar ativamente do desenvolvimento de crianças e jovens. A imagem do professor como um "DEUS", detentor do poder e sabedoria parece não ser mais uma realidade entre os discentes pesquisados. Eles mostraram um professor bem mais humano, sociável, amigável, que muitas vezes atua até mesmo como pai e amigo de seus alunos, auxiliando-os a superar as dificuldades da vida.

Os dados coletados demonstram que a Carreira Docente não é vista apenas como uma missão quase impossível, na qual apenas alguns corajosos poderiam enfrentar. Apesar das dificuldades e discriminações que ainda rondam a figura do professor, seu potencial criador e modificador de uma dada realidade vêm atraindo jovens a seguirem a Carreira Docente e até mesmo modificando as representações iniciais de alguns deles que ingressaram no curso com muitos pré-conceitos.

Cabe, a cada um de nós educadores, mostrar aos nossos alunos os dois lados da carreira, os prós e os contras, clarificando o que há de mito e o que há de verdade. Esclarecer e fortalecer a importância do papel do professor em nossa sociedade, bem como o compromisso necessário com a educação. E, para aqueles que ousarem ingressar na Licenciatura, incentivá-los a fazer parte da mudança no panorama geral da educação do nosso país. 


\section{REFERÊNCIAS}

ALMEIDA, Ma. E. G. G. de; PINHO, Luís V. de. Adolescência, família e escolhas: implicações na orientação profissional. Rev. Psicologia Clínica, Rio de Janeiro, n. 2, 2008.

ALVES, R. Conversas com quem gosta de ensinar. 8. ed. Campinas, São Paulo: Papirus, 2006.

CUNHA, M. Isabel. O bom professor e sua prática. 18 ed. Campinas, São Paulo: Papirus, 2006.

GARCIA, Ma. M. A.; HYPÓLITO, A. M.; VIEIRA, J. S. As identidades docentes como fabricação da docência. Educação e Pesquisa, São Paulo, v. 31, n. 1, p. 45-56, jan./abr. 2005.

JODELET, D. Representações sociais: um domínio em expansão. In: ALMEIDA, Ma. E. G. G. de; PINHO, Luís V. de. Adolescência, família e escolhas: implicações na orientação profissional. Rev. Psicologia Clínica, Rio de Janeiro, n. 2, 2008.

JOVCHELOVICH, S. Representações Sociais: Saberes sociais e polifasia cognitiva. EDUCadernos - Série Estudos e Pesquisas. Blumenau, Caderno n. 2, 2001.

LISBOA, M. D. Ser quando crescer... A formação da identidade ocupacional. In: ALMEIDA, Ma. E. G. G. de; PINHO, Luís V. de. Adolescência, família e escolhas: implicações na orientação profissional. Rev. Psicologia Clínica, Rio de Janeiro, n. 2, 2008.

MARQUES, M. O. Formação do Profissional da Eucação. 4. ed. Ijuí: Ed. Unijuí, 2003.

MAURÍCIO, L. V. A opção pelo magistério representada por professoras de ensino fundamental em memoriais. Educação em Revista: Belo Horizonte, v. 25, n. 01, p. 115-138, abr. 2009.

MOSCOVICI, S. A representação Social da Psicanálise. Tradução: Álvaro Cabral. Rio de Janeiro: Zahar Editores, 1978.

RAMOS, J. G. A representação social da mulher no contexto da relação conjugal violenta na cidade de Manaus. Recife: Bagaço, 2003.

REALI, A. M. M. R.; MIZUKAMI, M. G. N. (Org.). Formação de Professores Tendências Atuais. 1. ed. São Carlos, SP: EDUFSCAR, 1996.

PIMENTA, S. G. A didática como mediação na construção da identidade do professor: uma experiência de ensino e pesquisa na licenciatura. In: ANDRE, M. E. D. A.; 
FERNANDES, F. S. Futuros educadores ou professores? Um estudo sobre as representações sociais...

OLIVEIRA, M. R. N. (Orgs.). Alternativas no ensino da Didática. Campinas: Ed. Papirus, 1997. p. 37-69.

VASCONCELLOS, C.S. Para onde vai o professor?:Resgate do professor como sujeito de transformações. São Paulo: Libertad, 2001.

Texto recebido em 23 de fevereiro de 2010

Texto aprovado em 10 de abril de 2010 